\title{
A.8. identidades e memórias EM torno de www.aibr.org UMA MINA: O CASO DE ALJUSTREL
}

\section{Inês Fonseca}

Investigadora, Centro de Estudos de Etnologia Portuguesa, Faculdade de Ciências Sociais e Humanas, Universidade Nova de Lisboa (Portugal) e Leitora de Língua Portuguesa, section d'espagnol et portugais du Département de Langues Vivantes, Unité de Formation et Recherche en Sciences du Langage, de l'Homme et de la Société, Université de Franche-Comté (França). Direcção: CEEP - FCSH / UNL, Av. de Berna 26 C, Lisboa. E-mail: illaichi@hotmail.com.

\section{Resumo}

Num momento em que cada vez mais a actividade das minas europeias é entendida como um fenómeno do passado, a patrimonialização das minas (incluindo as infra-estruturas de produção, o equipamento industrial, a arquitectura, os próprios jazigos e a paisagem alterada pela actividade industrial) resulta de um processo de atribuição de novas funcionalidades a esses elementos, que perderam o seu interesse produtivo original e são agora convertidos para a actividade turística de características culturais - tornam-se objectos ou sítios de museu.

Neste processo, em que a mina é apropriada por grupos e agentes estranhos à sua actividade produtiva clássica (organizações políticas, agentes culturais, cientistas, turistas, etc.), identidades e memórias associadas ao trabalho nas minas são alvo de reconstruções e recriações.

Palavras chave

Identidade, Memória Social, Mineiros, Património

\begin{abstract}
When the mining activity has been more and more frequently understood as something belonging to a certain time in the past, the conversion of mining patrimony (including the structures of production, the machinery, the architecture, the pits and the landscape modified by industrial activity) is the result of attributing new functions to previous elements which lost their productive interest and are now being converted on behalf of a cultural tourism - they become either objects or places of museums

Along this process, the mine has been being appropriated by groups and agents out of its traditional activity of production (such as political organizations, cultural agents, scientists, tourists, etc.) and its identities and memories, associated with the mining work itself are becoming the aim of reconstructions and recreations.
\end{abstract}

Key words

Identity, Miners, Patrimony, Social Memory 


\section{Introdução}

indústria extractiva de minério é uma actividade económica cuja possibilidade depende dos
recursos naturais disponíveis. O esgotamento de um filão implica o fim da produção, o encerramento ou deslocalização da empresa e o consequente desaparecimento dos respectivos postos de trabalho. Na Europa, para a esmagadora maioria das unidades de produção mineiras e respectivas comunidades, o momento actual é de recessão e recuo da actividade de mineração. Por outro lado, o reconhecimento da importância que a indústria mineira representa ainda - pelas transformações sociais, económicas, culturais e tecnológicas que provocou - está a dar origem a um forte movimento de salvaguarda de tudo o que está relacionado com a sua existência.

Entre os cientistas sociais, o debate sobre a indústria mineira centrou-se inicialmente sobre o questionamento da existência de uma cultura mineira: baseada em comunidades fortemente vincadas por uma actividade económica (a extracção de minério) que influencia todos os aspectos (laboral, social, cultural) da vida dos indivíduos (Fonseca, 2004 e no prelo). Actualmente, a problemática tem sido recolocada, no contexto da paragem desta actividade produtiva e da necessidade de perspectivar o futuro dessas populações (García et al., 2002; Rabier, 2000; Fieldhouse e Hollywood, 1999).

A resposta mais frequente a este problema tem sido a da patrimonialização dos objectos, dos espaços e da cultura das comunidades mineiras que, dessa forma, mantêm uma função economicamente produtiva: tornam-se produtos da designada indústria do turismo cultural. Desta forma, muitos investigadores (historiadores, arqueólogos, sociólogos e antropólogos, sobretudo) têm dedicado as suas pesquisas à recolha e recuperação de elementos do passado das minas e das populações mineiras com vista à sua preservação para a posteridade. A mina transforma-se então num terreno de trabalho privilegiado para estas ciências e em especial, para a antropologia ${ }^{1}$. Esta disciplina tem desempenhado um papel fundamental na salvaguarda de uma identidade mineira, contribuindo para o reforço e perpetuação de memórias e identidades construídas, num contexto marcado em grande medida pelas necessidades e interesses das empresas mineiras e dos projectos de patrimonialização para fins turísticos, apresentados pelos poderes centrais e locais implicados.

A criação de um património cultural, partindo dos elementos produtivos relacionados com a mineração, baseia-se no aproveitamento de elementos das identidades e memórias locais e na sua recriação. É construída uma nova imagem (que se pretende apelativa e harmoniosa) para estas novas regiões turísticas. Estes fenómenos de retradicionalização (Boissevain, 1992) ocorrem essencialmente ao nível dos discursos produzidos sobre o passado das comunidades e das suas populações.

\footnotetext{
${ }^{1}$ A antropologia social e cultural dedicada á temática mineira faz a sua entrada no panorama dos estudos das ciências sociais sobre o tema, precisamente, com o suposto desaparecimento do seu objecto de estudo. Por isso, a ênfase colocada na investigação de salvamento e de preservação cultural (J.Copans; 2000). 
Nos recentes processos de mudança social, a história tem vindo a representar um papel fundamental enquanto factor explicativo de identidades locais particulares e surge, ainda, associada a um movimento generalizado de reacção aos efeitos da globalização cultural ${ }^{2}$. Num texto que intitula L'histoire a changé de lieux, Daniel Fabre (2001) alude ao recente fenómeno de descoberta da história por parte dos grupos locais. Apesar de reconhecer que o elemento histórico sempre esteve presente nas identidades locais, o autor refere que se verifica actualmente uma deslocação da origem destes discursos, bem como uma transformação ao nível daqueles que proferem os discursos e das formas como estes são proferidos.

Um dos elementos que caracteriza esta transformação é a participação activa dos poderes e forças políticas nos processos de construção de identidade. A reconstrução do passado, motivada pelo processo de patrimonialização, surge sob o impulso dos agentes políticos locais; este facto conduz a uma consciência patrimonial diferente, associada à possibilidade de captar apoios financeiros para a região. Assim, além das próprias populações, intervêm ainda no processo de construção patrimonial das antigas localidades mineiras, entre outros: os representantes do poder político nacional e central (incluindo as diferentes forças partidárias com expressão regional), os mediadores que estabelecem uma ligação entre as várias instâncias de decisão e distribuição das verbas existentes ou, ainda, os agentes do poder científico e erudito nacional e local, que encontram nestes projectos um mercado de trabalho em expansão e uma forma de legitimação profissional.

O caso da vila mineira de Aljustrel $^{3}$ (situada na Faixa Piritosa Ibérica, no Sul de Portugal) apresenta especial interesse no que diz respeito aos fenómenos de patrimonialização da actividade mineira e de recriação das memórias e identidades daquela população.

\section{O mito das comunidades mineiras}

As ciências sociais têm apresentado a identidade profissional dos trabalhadores mineiros como sendo uma das mais fortes e inquestionáveis. O facto de se tratar de unidades de produção que geralmente funcionam em sistemas encerrados (concentracionários) e com organizações paternalistas de vários tipos facilitaria a formação de um corpo colectivo entre as massas trabalhadoras daquelas indústrias, com base em elementos culturais e de identidade próprios.

É verdade que as minas são um mundo à parte. O trabalho no subsolo é uma actividade de risco, que exige coragem para descer ao fundo diariamente, esforço físico no desempenho das tarefas e bravura e solidariedade nos momentos difíceis de acidentes e de lutas. Os trabalhadores mineiros são os heróis que protagonizam esses episódios. Com base em elementos reais (uns) e imaginados

\footnotetext{
${ }^{2}$ Cada vez mais as pequenas localidades têm dificuldade em manter as suas especificidades clássicas: a abertura ao mundo e a facilidade de comunicação provocam o sentimento de que qualquer objecto material, produto ou prática cultural particular podem existir (ser obtidos ou vistos) em qualquer parte do mundo. Neste contexto, emerge um movimento aparentemente em sentido contrário de regresso às origens, ao original e único de cada local.

${ }^{3} \mathrm{O}$ presente texto resulta de uma pesquisa realizada pela autora, entre 2001 e 2004 (na vila de Aljustrel, no Sul de Portugal), no âmbito da sua dissertação de doutoramento em etnologia (Fonseca, 2004). 
(outros) foi sendo construída uma imagem mitificada dos trabalhadores nas minas. Diz-se deles que constituem uma raça à parte, que são trabalhadores e militantes modelo. Contudo, uma análise mais detalhada sobre o assunto permite-nos entendê-lo de outra maneira percebendo, sobretudo, as ambiguidades e contradições que esta identidade aparentemente incontestada acarreta.

A pesquisa que realizei em Aljustrel elegeu como objecto principal as questões da identidade da vila (que se diz terra mineira e terra de luta), bem como as questões da memória e identidade profissional da sua população trabalhadora (na mina ou nos campos) e a evolução sofrida com a suspensão da actividade mineira.

Logo nos primeiros tempos da minha presença no terreno, verifiquei um facto muito interessante do ponto de vista da problematização sobre a identidade da vila: durante todo o século $X X$ a população de Aljustrel havia-se repartido entre o trabalho mineiro e o trabalho agrícola, no entanto, encontravame manifestamente perante uma identidade profissional (a de mineiro) apropriada por toda uma comunidade e reclamada para toda a vila e isso acontece mesmo num momento em que essa actividade se encontra em declínio (com a suspensão em 1990 dos trabalhos de mineração).

\section{A identidade profissional de uma vila: ambiguidades e contradições}

Os processos colectivos de identificação e de rememoração numa comunidade mineira com as características de Aljustrel (em que os operários mineiros estavam perfeitamente inseridos no contexto rural da região e, ainda por cima, num momento em que a actividade de mineração estava suspensa) produzem discursos ambíguos e contradições relativamente à identidade da vila e da sua população.

A primeira ambiguidade que encontrei é relativa à identificação da população da vila com os trabalhadores mineiros.

A actividade industrial mineira, entre 1867 e 1993, realizou-se com sucessivas paragens da produção, provocando grande instabilidade ao nível da mão-de-obra operária empregada nas minas. Ao longo de todo esse período a actividade mineira desenrolou-se em complemento com a actividade agrícola, sendo a mão-de-obra assalariada disponível no concelho utilizada ora numa ora noutra (consoante as respectivas necessidades). Assim, apesar de a actividade mineira ser a actividade económica dominante em Aljustrel (pela quantidade de pessoas que afectava e pela maior regularidade dos ordenados), esta nunca veio a assumir um carácter exclusivo no que dizia respeito à ocupação da população trabalhadora.

Contudo, verifiquei que a maior parte dos trabalhadores assume-se de facto em primeiro lugar como mineiros; mas também não deixam de referir os momentos de desemprego em que foram trabalhar 
para a agricultura ou para as obras públicas e as alturas do ano em que acumularam o trabalho da mina com o das ceifas nas herdades da região.

Simultaneamente, deparei ainda com uma contradição relativamente à identidade mineira reclamada para a vila: não só estava em presença de uma reactivação de um discurso de identidade relativo a uma actividade profissional em extinção e que era reclamada para toda uma população, como também estavam as memórias relativas a essa actividade sujeitas a um processo de reelaboração colectiva (correndo o risco de serem anuladas e contraditadas por outras mais consensuais).

$\mathrm{Na}$ realidade, em Aljustrel, todos os discursos fazem referência à identidade mineira da vila, no entanto, ao longo do trabalho de campo confrontei-me com a existência de uma verdadeira amnésia social relativamente às questões concretas do trabalho nas minas, dos mineiros e das suas lutas.

Quando, inicialmente, responderam à minha explicação sobre o trabalho que me encontrava ali a fazer, dizendo "isso, agora, já não há mineiros", nunca supus que essa situação representasse de facto tão grande correspondência entre a realidade social e a representação construída pela colectividade - o que originava outro paradoxo: entre uma identidade mineira sentida pela população (que começava a estar ultrapassada) e uma identidade mineira mitificada (que era reclamada para a vila pela mesma população e pelos seus responsáveis políticos locais) com o objectivo de desenvolver projectos turísticos.

\section{Etnografia da Memória}

Identifiquei vários factores concretos que justificam a existência de uma amnésia social (Fentress e Wickham, 1992; Halbwachs, 1964 e 1994) sobre o passado da exploração mineira e dos trabalhadores na mina. Por um lado, existe uma elevada taxa de mortalidade entre os mineiros (motivada por acidentes e doenças profissionais, que contribuem para uma reduzida esperança média de vida desta população) e, por outro, verificou-se uma elevada taxa de emigração entre os aljustrelenses nos anos de 1963-64 (que teve origem no desemprego e na repressão a que estiveram sujeitos os mineiros nesse período, por reivindicarem melhores condições de vida). Como consequência deu-se uma ruptura que se traduziu por uma não transmissão da memória sobre esse tempo e os factos ocorridos, o que faz com que hoje em dia os filhos e netos não tenham um conhecimento concreto sobre o que se passou nas vidas dos seus pais e avós.

O passado de trabalho e de lutas vivido em Aljustrel, para além daquele discurso genérico sobre a heroicidade dos operários mineiros, é um tema pouco abordado espontaneamente. Essas conversas são alvo de receios e hesitações. Convém não esquecer que muitos dos temas que interessavam à pesquisa estavam directamente relacionados com momentos difíceis nas vidas das pessoas (pela miséria vivida e pelas dificuldades enfrentadas, na realização de um trabalho árduo e numa época em que quaisquer protestos ou reivindicações eram imediatamente reprimidos). 
Estes factos explicam por que foi difícil encontrar entrevistados competentes e disponíveis para colaborar na investigação. Aquilo que verifiquei rapidamente foi que já não existiam muitos indivíduos que tivessem participado ou assistido de perto aos acontecimentos das décadas de 50-60, pois a maioria das pessoas ou já tinha falecido ou saíra da vila nessa época e não regressou a Aljustrel ${ }^{4}$. Também uma boa parte das pessoas contactadas já não estava suficientemente lúcida. $E$, além disso, acima dos 60 anos de idade, a maioria das pessoas que trabalharam nas minas sofre de silicose, o que traz consequências no modo de falar (sussurrado) o que impossibilitou, por exemplo, o registo das conversas com um gravador (para que se ouvisse nitidamente alguma coisa, tornava-se necessário pedir que falassem mais alto e, quando o faziam, desencadeavam ataques de tosse que os afligiam e impediam de continuar a falar ${ }^{5}$ ).

\section{Aljustrel: terra mineira, terra de luta?}

Quando se investiga sobre as memórias do trabalho não são apenas os vestígios materiais da actividade que contam. O património edificado das unidades de produção bem como os aspectos tecnológicos a ela ligados têm obviamente interesse. Mas não podemos esquecer-nos de que o trabalho é realizado por homens e mulheres e que todas as actividades produtivas deixam não só um importante património arquitectónico e tecnológico como também social e cultural - desde linguagens próprias, gestualidades, formas de vestir, maneiras de pensar, modos de organização formal ou informal (como as associações de trabalhadores ou de patrões e as redes de sociabilidade). Foi nesta perspectiva, reconhecendo a extrema importância dos aspectos imateriais relacionados com a construção e a recriação a que estão sujeitas as memórias associadas com a actividade mineira, que orientei a pesquisa.

Em Aljustrel, a história da vila surge irremediavelmente associada à existência do jazigo de minério. A memória oficial edificada na actualidade, sobre o passado da vila e da sua população ligado à mineração, é uma memória depurada dos seus aspectos menos consensuais e passíveis de criar tensões e conflitos e, simultaneamente, corresponde a uma mitificação do trabalho na mina. Todos os elementos que contribuem para a edificação de uma imagem menos agradável sobre as minas e o trabalho dos mineiros são afastados da imagem oficial apresentada.

Por este motivo, na rememoração que é feita actualmente sobre o passado da vila, pouco se fala dos inúmeros acidentes e desastres ocorridos que vitimaram muitos trabalhadores (com excepção para as referências genéricas feitas ao perigo iminente do trabalho nas minas e às necessárias regras de segurança ou à elevada taxa de sinistralidade entre os trabalhadores mineiros). A imagem apresentada sobre esta actividade é associada a elementos que enfatizam a coragem dos

\footnotetext{
${ }^{4}$ Para se ter uma ideia desta dificuldade em encontrar entrevistados, pode dizer-se que da greve em 1960, na qual foram presos cerca de 150 mineiros, apenas foi possível localizar e entrevistar um deles (apesar de terem sido identificados familiares, amigos e vizinhos de muitos dos outros).

${ }^{5}$ Esta informação assume especial interesse (para além da importância que teve para as práticas metodológicas seguidas durante a pesquisa), pois revela um dado concreto e observável (para além dos discursos) sobre os efeitos nefastos para a saúde dos indivíduos do trabalho no subsolo - tema que se reveste de bastante interesse no que diz respeito aos trabalhadores mineiros. 
trabalhadores ao desempenharem uma actividade perigosa e de confronto com a natureza. É afirmada a ideia de que o trabalho nas minas tem um carácter de aventura em que homens e tecnologia saem vitoriosos (ideia esta que tem potencialmente grande eficácia para a publicidade sobre a vila para efeitos turísticos).

Simultaneamente, também a história dos momentos de luta protagonizados pelos operários mineiros aljustrelenses é alvo de uma reconstrução. A história local está marcada por importantes lutas e até alguns acontecimentos trágicos, episódios como: a greve de 1922-1923 (que se prolongou por 4 meses), a greve de zelo entre 1958 e 1960, a paralisação do trabalho em Abril de 1960 (com a consequente prisão de 150 trabalhadores nas cadeias da PIDE-DGS) ou o tiroteio policial durante uma manifestação em Abril de 1962 (que resultou na morte de 2 pessoas). No entanto, quando estes são referidos, é no sentido de se exaltar o carácter corajoso dos trabalhadores por desempenharem uma profissão de alto risco e pelo seu envolvimento em movimentos colectivos, sendo estes aliviados de qualquer conotação ideológica. Para justificar a forte mobilização e resistência dos mineiros durante a ditadura do Estado Novo (1926-1934), por exemplo, é feita referência à sua capacidade de solidariedade, omitindo qualquer referência explícita à existência de uma rede de resistência ligada a um partido político na clandestinidade: o Partido Comunista Português (PCP). Isto apesar de a vila reclamar para si uma dupla identidade: operária (terra de mineiros) e revolucionária (terra de luta).

Nesse sentido opera-se uma rejeição de determinados aspectos do passado, mais marcados política e ideologicamente e com os quais nem todos se reconhecem. Opondo-se às memórias individuais dos mineiros (e não só), que estão a ser anuladas, emerge uma memória oficial (universal e consensual) libertada dos seus aspectos controversos (nomeadamente, a sua conotação partidária).

\section{Memória Polifónica}

Contudo, essa memória oficial (que é facilmente aceite por todos) não se impõe de forma exclusiva perante a população da vila, existe sempre espaço para a coexistência com outras memórias e com outras identidades, que estão na origem de discursos e práticas diversos. Mas a mina e o passado da vila associado à mineração mantêm-se como o denominador comum de todas as formas de rememoração.

As memórias dos diferentes grupos, que perduram actualmente na vila, são alvo de um processo de transformação que as afasta ou aproxima dos acontecimentos que viveram no passado. Cada uma destas memórias tem uma correspondência num conjunto de atitudes e de comportamentos de cada grupo e contribui para a definição das diferentes identidades. Em seguida, darei conta de três exemplos, que correspondem, cada um, a um grupo de pertença com uma identidade e com formas de rememoração próprias. 


\subsection{Os grupos corais}

A presente situação da empresa mineira (com a laboração suspensa) trouxe também consequências para o Grupo Coral do Sindicato dos Mineiros, pois passou a tornar-se cada vez mais difícil encontrar quem quisesse integrar o grupo entre os cerca de 80 trabalhadores que ainda ali se empregam nos trabalhos de manutenção da mina. Além disso, como algumas pessoas comentaram, "-Se já não há mineiros, como é que continua a haver um grupo do Sindicato dos Mineiros?". A maior parte dos antigos membros daquele grupo coral, já não pertence à empresa: alguns, porque "abandonaram a mina" e emigraram (tendo regressado mais tarde a Aljustrel) e outros, porque se reformaram.

Actualmente, aqueles que residem em Aljustrel, encontram-se nos cafés e tascas da vila e dos bairros mineiros, mantendo o gosto pelo convívio e pelo canto alentejano. Foi assim que surgiu a ideia de formar um novo grupo coral (designado Os Cigarras). Este é constituído por antigos mineiros e assalariados agrícolas. A par do ainda existente Grupo Coral do Sindicato dos Mineiros, o grupo d'Os Cigarras é um dos representantes da vila de Aljustrel, nas apresentações de grupos corais alentejanos ou nas comemorações locais. Realizam os seus ensaios todas as quintas-feiras na sede do Sport Clube Mineiro de Aljustrel e alguns dos elementos mantêm um convívio todos os sábados juntam-se para confraternizarem, comer uns petiscos, beber uns copos e cantar.

Durante a minha estadia no terreno, no dia 24 de Abril de 2004, convidaram-me a integrar um desses encontros: a conversa, motivada pela minha presença, girou em torno das recordações sobre o seu envolvimento político e as suas actividades na clandestinidade. Actualmente, este grupo mantém-se unido por uma memória comum ainda partilhada por algumas pessoas da vila (o trabalho na mina e o passado de lutas, não só dos mineiros, mas de toda a vila), mas também aceitam perfeitamente a ruptura com o passado e integram as mudanças que ocorreram nas suas vidas.

\subsection{As romagens de homenagem aos mortos de 1962}

Ainda no dia 24 de Abril de 2004, desloquei-me ao cemitério com Bárbara Inácia Mestre, onde foi pôr flores na campa de sua mãe (Maria Antónia Mestre ${ }^{6}$ ). Acompanhou-nos também uma vizinha, cujo marido foi militante do partido comunista (tal como Maria Antónia e Bárbara Inácia).

Esta prática pretende ser uma rememoração de acontecimentos do passado e dos seus protagonistas. É reproduzida uma mesma acção: as romagens ao cemitério em homenagem aos mortos de 1962.

Até ao final da ditadura, estas romagens realizaram-se sempre sob vigilância policial. Até que, em 25 de Abril de 1974, a queda do regime e a mudança para a democracia trouxeram o fim dos

\footnotetext{
${ }^{6}$ Esta foi uma das pessoas feridas em 28 de Abril de 1962 e, em consequência desse acontecimento, esteve presa pela polícia política (primeiro, no hospital e mais tarde, na prisão de Caxias).

(c) Inês Fonseca. Publicado en AIBR. Revista de Antropología Iberoamericana, Ed. Electrónica

Vol 1. Num. 3. Agosto-Diciembre 2006. Pp. ii-xi Madrid: Antropólogos Iberoamericanos en Red. ISSN: 1578-9705
} 
constrangimentos políticos. Imediatamente, no dia 28 de Abril, os aljustrelenses realizaram a primeira romagem ao cemitério em liberdade, homenageando os mortos de 1962 e os da guerra colonial. Nesses primeiros anos, estas romagens ocorreram com a presença de verdadeiras multidões como em 1974, mas com o tempo foram perdendo o impacto e a participação.

Actualmente, estas idas ao cemitério ainda se realizam (não no dia 28 de Abril, mas próximo do dia 25 de Abril), com a intenção por parte daqueles que participam de se aproximar tanto quanto possível da primeira romagem realizada (logo no ano desse acontecimento).

Já não se trata verdadeiramente de romagens, pois perderam o carácter de acção colectiva que tiveram nos primeiros anos, passando a ser um acto praticado individualmente. Os participantes são, essencialmente, mulheres que prestam homenagem aos seus familiares (militantes do PCP do tempo de clandestinidade, entretanto falecidos), ao Presidente da primeira Comissão Administrativa da Câmara Municipal a seguir ao 25 de Abril de 1974 e aos mortos de 1962.

\subsection{Fotos de casamento na zona industrial abandonada}

Estas são algumas das formas de rememoração por parte das gerações mais velhas, observadas em Aljustrel, mas também os jovens participam na identidade mineira da vila.

Com a actividade da empresa concessionária das minas paralisada há mais de 10 anos, a possibilidade de aí vir a empregar-se começa a estar ausente das expectativas ou ambições de futuro das novas gerações. Desta forma, são os jovens quem mais facilmente adere à imagem da mina folclorizada, edificada para fins turísticos. Também eles têm uma visão muito própria sobre a mina e o legado patrimonial que ela representa.

Durante a estadia em Aljustrel, observei um episódio interessante a este respeito. Todos os anos, o mês de Agosto constitui uma espécie de época alta para a realização de festas de casamento. Assim, nessa época do ano, as montras dos fotógrafos da vila enchem-se de fotografias de noivos, tiradas em locais considerados bonitos: searas alentejanas, campos de girassóis, antigas igrejas, monumentos da região, piscinas ou, surpreendentemente, a paisagem lunar da área de produção das minas.

Não são muitos os casais que optam por este cenário, mas a originalidade da ideia capta a atenção de todos. Interroguei-me sobre os motivos que levariam um jovem casal a querer fixar desta forma a imagem do seu casamento. Em conversa com um dos fotógrafos, compreendi que este cenário não era muito do seu agrado e, portanto, a escolha dos noivos não era devida às suas pressões. Também falei com um destes noivos (Rui Nunes) que me revelou que tal como grande parte das pessoas em Aljustrel, ele e a sua esposa tiveram alguém na família próxima (o avô dela e um irmão dele) que trabalhou na empresa mineira, mas isso são coisas do passado; o motivo para a escolha daquele 
cenário para as fotografias do seu casamento deveu-se à originalidade. Vivendo em Aljustrel, uma "vila mineira", pensaram que seria interessante e fora do comum serem fotografados num local que estava relacionado com uma particularidade da terra onde nasceram e se casaram.

Assim, nos discursos do grupo dos jovens, a mina surge mais como uma presença simbólica, que Ihes permite afirmarem uma identidade de pertença: ser de Aljustrel tem uma especificidade particular porque se trata de uma terra de mineiros e, por isso, é diferente das outras. A grande maioria dos jovens já não entende a mina como uma promessa de futuro, mas mantém-se afectivamente ligada a ela.

\section{Bibliografia}

Boissevain, Jeremy (1992). Revitalizing european rituals. London and New York: Routledge.

Castillo, Juan José (2004). La memoria del trabajo y el futuro del patrimonio. Sociología del Trabajo, nº 52: 3-35.

Copans, Jean (2000). L'anthropologie sociale n'est-elle pas née, au fonds, des mines?. Comunicação apresentada no Colloque International du Béthume: Anthropologie du bassin minier. Formes de mobilisation dans les régions d'activités minières (IFRESI / CNRS (edição on-line: http://www.ifresi.univlille1.fr/PagesHTML/ABM/actescoll.html).

Fabre, Daniel (2001). L'histoire a changé de lieux. Une histoire à soi. Figurations du passé et localités. Alban Bensa e Daniel Fabre, Dirs. Paris: Éditions de la Maison des Sciences de l'Homme.

Fentress, James e Wickham, Chris (1992). Memória Social. Novas perspectivas sobre o passado. Lisboa: Editorial Teorema.

Fieldhouse, Edward e Hollywood, Emma (1999). Life after mining: hidden unemployment and changing patterns of economic activity amongst miners in England and Wales, 1981-1991. Work, Employment \& Society, 13(3): 483-502.

Fonseca, Maria Inês Pinto (2004). "Levávamos Logo a Foice P’ra Mina”: Identidades e Memórias dos Mineiros de Aljustrel. Dissertação de Doutoramento, Departamento de Antropologia, Faculdade de Ciências Sociais e Humanas, Universidade Nova de Lisboa.

Fonseca, Maria Inês Pinto (no prelo). "Todos queriam trabalhar porque todos tinham fome": Mineiros e assalariados agrícolas no mercado laboral de Aljustrel (Portugal). Revista Mexicana de Sociología.

García, José Luis García ; Coira, Miguel Maria López; Devillard, Marie José; Reyes, Javier Escalera; Muñoz, Adelina García e Pérez, Nieves Herrero, Coord. (2002) Los últimos mineros. Un estudio antropológico sobre la minería en España. Madrid: Centro de Investigaciones Sociológicas / Siglo XXI.

Halbwachs, Maurice (1968). La mémoire collective. Paris: Presses Universitaires de France. 
Halbwachs, Maurice (1994). Les cadres sociaux de la mémoire. Paris: Edition Albin Michel.

Knapp, A.Bernard; Pigott, Vincent C. e Herbert, Eugenia W., Eds. (1998). Social approaches to an industrial past. The archaeology and anthropology of mining. London: Routledge.

Lowenthal, David (1993). The past is a foreign country. Cambridge: Cambridge University Press.

Rabier, Jean-Claude,Coord. (2000). Actes du Colloque International du Béthume: anthropologie du bassin minier. Formes de mobilisation dans les régions d'activités minières (IFRESI / CNRS (ed.on-line: http://uww.ifresi.univ-lille1.fr/PagesHTML/ABM/actescoll11.html).

Román, Manuel Aragón e Ballesteros, Esteban Ruíz (1995). Mina y mineros. Imágenes y significados en la Cuenca Minera de Riotinto. s.l.: Fundación Rio Tinto. 